\title{
Factors Affecting the Prevalence of Chronic Kidney Disease among Adult Population in Sri Lanka: With Special Reference to Badulla District
}

Sri Lanka Journal of Social Sciences and Humanities Volume 1 Issue 2, August 2021: 87-97 ISSN: 2773 692X (Online), 27736911 (Print) Copyright: (C) 2021 The Author(s)

Published by Faculty of Social Sciences and Languages, Sabaragamuwa University of Sri Lanka Website: https://www.sab.ac.lk/sljssh DOI: http://doi.org/10.4038/sljssh.v1i2.41

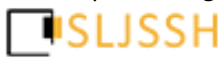

\author{
Vithanage, M.V.A.R. ${ }^{1,{ }^{*}}$, Rathnayake, R.M.L. ${ }^{1}$ and Jagoda, D.J. ${ }^{1}$ \\ ${ }^{1}$ Department of Economics and Statistics, Sabaragamuwa University of Sri Lanka, Belihuloya, 70140, Sri Lanka.
}

Received: 30 November, 2020, Revised: 20 April, 2021, Accepted: 27 June, 2021.

How to Cite this Article: Vithanage, M.V.A.R., Rathnayake, R.M.L. and Jagoda, D.J. (2021). Factors affecting the prevalence of chronic kidney disease among adult population in Sri Lanka: With special reference to Badulla District. Sri Lanka Journal of Social Sciences and Humanities, 1(2), 87-97.

\begin{abstract}
Chronic Kidney Disease (CKD) is one of the non-communicable diseases. According to records, kidney disease affects millions of people worldwide including Sri Lanka every year. The number of kidney patients rapidly increased in the last three decades in Sri Lanka and it has been blowout to Badulla District during the previous years. Therefore, this study is mainly focused to investigate the factors that affect the prevalence of CKD in Badulla district in Sri Lanka. A sample was drawn using the multi-stage cluster sampling method. The study was conducted using a quantitative approach and a questionnaire survey. Descriptive statistics and binary logistic regression were used to achieve the objectives. According to the descriptive statistics, $35.73 \%$ of the sample are recorded for having kidney disease and $64.27 \%$ are recorded for not having kidney disease. The majority of kidney patients are male. Binary logistic regression has found that amount of drinking water per day and the duration of using alcohol are significant factors for having kidney disease. Further, it reveals that people who drink less amount of water were more likely to develop kidney disease than people who drink more amount of water and long duration of alcohol intake is more evident to have kidney disease than those who have not used alcohol. Further, the study suggested increasing the amount of drinking water per day, and to reduce the alcohol intake as a solution for getting rid of kidney disease.
\end{abstract}

Keywords: Alcohol, Binary Logistic Regression, Chronic Kidney Disease

\section{INTRODUCTION}

The kidneys are important parts of the human body's urinary system and kidneys play an important role in the human body. Sometimes kidney function can change quickly. Therefore, a sudden change in kidney function is called an Acute Kidney Injury. This is often temporary but sometimes it leads to lasting kidney damage. Because of that, most often kidney function gets worse over the years. It is a chronic condition. It can be called CKD. This disease does not have any warning signs. Sometimes people lose up to $90 \%$ of their kidney function before getting any symptoms (World Kidney Day Organization, 2020). CKD is one of the non-communicable diseases and also it is a slowly progressive disease. It can progress to end-stage kidney failure, which is dangerous without artificial filtering or a kidney transplant.

According to Global Burden of Disease, 2015 study records, kidney disease affects millions of people worldwide and in 2015, 1.2 million people died from kidney disease (WHO, 2018). So, this is a fatal disease. In the 1990 s, it is evident an increase in the prevalence of CKD in certain areas in several countries of the world, such as Pakistan, Nepal, Bhutan, Afghanistan, Egypt, India, and also Sri Lanka (Wimalawansa, 2019; Abraham et al., 2016). It was ranked 27th in the list of causes of the total number of deaths worldwide in 1990 but rose to 18th in 2010. This degree of movement up the list was second only to that for HIV and AIDS (Global Burden of Disease Study, 2010).

The number of kidney patients rapidly increase in the last three decades with the first patient in Sri Lanka was reported in the first quarter of the 1990s (Daily News, 2019). Any permanent solution has not been found yet. According to Rajapakse et al. (2016), the disease is mainly prevalent in North Central, parts of north-western, Uva, Central, Eastern and Northern provinces. Further, the prevalence of kidney disease is $15.1-22.9 \%$ in some districts in Sri Lanka (Rajapakse et al., 2016). However, considering the past researches, although CKD has become a major public health issue in Sri Lanka, the prevalence of this disease is not well reported. (Chandrajith et al., 2011; Rajapakse et al., 2016; Rango et al., 2015). Some studies found that the prevalence of CKD in Sri Lanka doubles every four to five years (Wimalawansa, 2015). So, at present, 150000 people are suffering from

Still, in Sri Lanka CKD is an unsolved problem and it seems that the disease is severely afflicting patients' lives are at risk due to lack of proper treatment. Therefore, the Sri Lankan government also tries to help kidney patients in several ways. The Anuradhapura Kidney Protection Foundation (AKPF) in the Anuradhapura Kidney treatment and research institute has started a welfare program for kidney patients.

\footnotetext{
*Corresponding author: Tel.: +94 (71) 2700785; Email: rangikavithanage96@gmail.com
}

(iD https://orcid.org/0000-0002-1108-9712 
As well, a special kidney hospital has been built in Polonnaruwa.

When considering Sri Lanka alone, more than 150,000 people suffer from CKD (Wimalawansa, 2015). This disease can be seen in males but now also apparent in both females and children. The panel experts decided on "High-Risk Areas", after considering the present pattern of distribution of cases.

\begin{tabular}{llll}
\multicolumn{2}{l}{ Table 1: High-risk areas in Sri Lanka } & & \\
\hline No & Province & District & District Secretariat Division \\
\hline 01 & North Central & Anuradhapura & All \\
02 & North Central & Polonnaruwa & All \\
03 & North-western & Kurunegala & Polpithigama \& Giribawa \\
04 & Eastern & Ampara & Dehiaththakandiya \\
05 & Eastern & Trincomalee & Padavi siripura \\
06 & Uva & Badulla & Mahiyangane \& Ridimaliyadda \\
07 & North & Mulathivu & Welioya \\
08 & North & Vavuniya & Vavuniya \& Vavuniya South \\
09 & Central & Mathale & Weligamuwa
\end{tabular}

Source: Ministry of Health (2017)

Further, the following table shows the information of kidney patients who are registered in clinics $2014-2018$. Some districts have not been able to collect data from this source. So it has not been recorded.

Table 2: Number of kidney patients

\begin{tabular}{lrrrrr}
\hline Area & $\mathbf{2 0 1 4}$ & $\mathbf{2 0 1 5}$ & $\mathbf{2 0 1 6}$ & $\mathbf{2 0 1 7}$ & $\mathbf{2 0 1 8}$ \\
\hline Anuradhapura & & & & & 4329 \\
Polonnaruwa & 1257 & n.a. & 5072 & 6663 & 1521 \\
Badulla & - & - & 11280 & 15524 & 28123 \\
Mulathive & 384 & 412 & 452 & 481 & 1340 \\
Trincomalee & - & - & 648 & 341 & 341 \\
Kurunegala & & & & 4061 & 5325 \\
Mathale & 0 & 921 & 751 & 521 & 335 \\
Ampara & 1506 & 1025 & 1792 & 2927 & 10070 \\
Monaragala & - & - & - & - & 1811 \\
Hambanthota & 4 & 65 & 39 & 15 & 8 \\
\hline
\end{tabular}

Source: District Statistics Handbook, 2019

According to table 2, there is an increasing trend of kidney disease reported in the Badulla District from 2016 to 2018. But most of the existing surveys have looked at the increase in kidney disease in Anuradhapura district and which is limited to the North Central Province. As a result of increasing kidney patients, they will be unable to work and they have to spend around Rs.10000 for dialysis and Rs.800000 for a kidney transplant (Daily News, 2012). On the other hand, the government spends over Rs.3500 million to treat kidney patients and the cost of drugs over Rs.7000 million annually (Daily News, 2012). Because of this, the issue is directly affecting downward economic development. Therefore, it is important to investigate the causes of the rapid increase in kidney disease in Badulla district. The main purpose of this study to identify the socio-economic and demographic factors, clinical factors, behavior factors, and environmental factors that influence the prevalence of kidney disease in Badulla district, Sri Lanka.

This paper is organized into five sections in which the first section has been already presented with the background, research problem, the importance of the study, and the main objective. The second section includes Literature Review; the most relevant theories related to the study and the empirical, methodological literature which depends upon historical evidence related to the topic. In the third section,
Conceptual Framework and Methodology are acknowledged. This section describes the methodology used to test the hypotheses, the dependent variable, and the independent variable. Data presentation and analysis are presented and justified in section four. It consists of the visual representation of the data and the statistical analysis for collected data. In the data presentation, graphs and tabulations are used. In the end, the fifth section includes the conclusions and the recommendations which are drawn by the results of the analysis.

\section{LITERATURE REVIEW}

The first theory put forward by Barry Freedman (2010), was about the kidney failure of African-Americans and its main point was that genetic factors are responsible for many of the racial differences in non-diabetic kidney disease. Feedman's belief was confirmed in 2010 after three groups of scientists claimed that the gene APOL1 was its main source. (Theories of Kidney Disease Confirmed,n.d.)

According to the empirical studies, under socio-economic and demographic characteristics gender, age, occupation, and income were some important characteristics relating to CKD. Bapat, Nayak, and Kedleya (2016) found that the socioeconomic and demographic characteristics appeared to be 
the most significant factor for CKD. Demographic factors of people with CKD vary widely around the world (Jha, GarciaGarcia, Iseki, Li, Naicker, Plattner, and Yang, 2013). According to Bandarage's point of view (2005), socio-economic dimensions such as patients' livelihoods, daily living patterns, and other social activities have a direct impact on CKD.

Considering gender, Coresh et al. (2007) found that CKD is significantly associated with gender both for men and women. According to Kafle et al. (2019), been CKD was significantly higher among females than males. Furthermore, Weerasekara (2017) revealed that Chronic Kidney Failure (CKF) mainly affected males than females. As well, Ranasinghe et al. (2019) explained that there was an increased proportion of male kidney patients within different age groups and also different district secretariats divisions. Jayasekara et al. (2015) showed that the male and female ratio of kidney disease was 2.4:1. However, Goro et al. (2019) found that gender was not significantly associated with CKD.

Age is another key determinant related to CKD. According to Coresh et al. (2007), CKD is significant with older age. And according to Kafle et al. (2019) the age of elder kidney patients was the same across the districts, the overall average is about 58 years. Although Raveendran and Balarajah (2012) concluded that the mean age of kidney patients was 62 years, Ranasinghe et al. (2019) revealed that the most vulnerable age group was 40-60. However, Yamagata, Ishida, Sairenchi, Takahashi, Ohba, Shiigai, and Koyama (2007) suggested that the prevalence of kidney damage was impacted by age.

Considering Occupation, being a farmer was a risk factor for CKD. (Wanigasuriya et al., 2007; Weerasekara, 2017; Ranasighe et al., 2019). Most patients affected by CKD is an adult and they have more than 10 years of experience regarding agriculture activities (Elledge, Redmon, Levine, Wickremasinghe, Wanigasariya, and Peiris-John, 2014).

Income is one of the key determinants related to CKD. According to Hettiarachchi and Abeysena (2018) and Weerasekara (2017) have revealed that the majority of kidney patients do not earn an adequate income.

Some of the important clinical factors identified concerning CKD under empirical studies are the time of having diabetes, time of having high blood pressure, duration of using Ayurveda medicines, family history of kidney failure, and also Body Mass Index (BMI). Johnson, Coresh, Levin and Eknoyan (2004) pointed out that the clinical factors appeared to be the highly affected factor for CKF.

Diabetes is a considerable clinical factor related to CKD. There was an association between CKD and diabetics. (Foley et al., 2005; Coresh et al., 2007; Raveendran and Balarajah, 2012; Jha et al., 2013). Further, Wanigasuriya et al. (2007) found that diabetes was found to be a significant risk factor for Chronic Renal Failure (CRF) in bivariate analysis, but in the multivariate analysis diabetics was not a significant variable of CRF.

Hypertension or high blood pressure also one of the key determinant related to CKD. Hypertension caused the majority of CKD patients. (Raveendran and Balarajah, 2012; Coresh et al., 2007). Jha et al. (2013) examined that hypertension also one of the leading causes of kidney failure in all developed and developing countries. Similarly, Duan et al. (2019) have shown that hypertension is also a risk factor of CKD in China. Considering the use of Ayurveda medicines, Wanigasuriya et al. (2007), revealed that using Ayurveda medicine is a significant predictor for kidney failure.
Family history of kidney failure also a considerable determinant related to CKD. According to Wanigasuriya et al. (2007), a family history of CRF was found to be a significant predictor for CRF. Not only that, genetic factors contribute to the prevalence of CKD. (Jha et al., 2013; Elledge et al., 2014)

$\mathrm{BMI}$ is another key determinant applicable to CKD. According to Coresh et al. (2007), a significant association was observed between BMI and prevalence of CKD. Obesity is an important risk factor for CKD. (Jha et al., 2013; Yamagata et al., 2007).

Under behavior factors or lifestyle factors, Drinking water, Smoking and using alcohol, Use of pesticides are some important characteristics relating to CKD. Peng, Shen, Wen, Wang, Fan, and Liu (2019) findings illustrate that various lifestyle risk factors contribute to the prevalence of CKD patients. Furthermore, identifying lifestyle risk factors are linearly associated with kidney disease.

Considering drinking water, Kafle et al. (2019) explained that groundwater dependence in affected CKD households was consistently higher than in non-affected households. Not only that, they found that CKD prevalence and using groundwater has positively correlated Northern districts. Most of the kidney patients who are engaged in agricultural activities consumed water from a well, canal drain water, and also spring water which is located in the agricultural land. Furthmore, drinking water is closely associated with the prevalence of kidney disease. (Weerasekara, 2017; Chandrajith et al., 2011).

Considering smoking and using alcohol, men were more likely to develop kidney disease due to alcohol and smoking. (Ranasinghe et al., 2019; Yamagata et al., 2007). Rango et al. (2015) suggested that alcohol, tobacco, and cigarette smoking speed the progression of CKD, and it causes faster endstage kidney damage.

The use of pesticides and fertilizers is another key determinant related to CKD. According to Wanigasuriya et al. (2007), occupation and pesticides are associated with CRF in the initial analysis but in the multivariate model, this variable was excluded. Pesticides were a high-risk factor for CKD. (Ranasinghe et al., 2019; Jha et al., 2013)

Snakebite and geographical distribution are some of the important environmental factors identified related to CKD empirical studies. As Soderland, Lovekar, Weiner, Brooks and Kaufman (2010) concluded that especially in the developing world, environmental factors are very important for CKD. And also, Chandrajith et al. (2011) identified that environmental factors are the most impacted to explain CKD.

According to Wanigasuriya et al. (2007), a history of snakebite $(P<0.001)$ was found to be a significant predictor for $C R F$ of unknown etiology.

Many researchers have investigated Kidney disease. However, many of them have considered only one primary factor or few that affect kidney disease, but not various factors together. This study has paid attention to a number of diverse factors that are expected to be associated with kidney disease. According to the Epidemiology Unit of the Ministry of Health (2017), there is a high risk of the spread of kidney disease in either all or a few of the Divisional Secretariats divisions of eleven districts (out of 25 districts) of SriLanka. But most of the studies are limited to the North Central Province or the Anuradhapura district. In general, some studies have been conducted on the prevalence of kidney disease in Sri Lanka. Even though the Badulla district has shown an increasing trend of kidney patients from 2016 to 2018, no study has been conducted so far. Therefore, this research is 
being carried out to identify the factors contributing to the increase in the prevalence of kidney patients in the Badulla district with the focus of filling the above research gap.

\section{MATERIALS AND METHODS}

\section{Sampling procedure}

The interested population of this study is both males and females over 18 years of age in Badulla district in 2018 $(567,643)$ (DCS, 2018). Badulla district is divided into $15 \mathrm{Di}$ visional Secretariat Divisions. The sample size for the study was 384 people and it has been decided based on the Morgan table. According to that system, if the number of people in the population varies between 250000-500000, then 384 people should include in the sample. However, this study invited 384 people relevant to the proportion and could take only 361 people as an accepted sample. This was because some were away from home and others were reluctant to provide their data.

This study is based on the probability sampling method. Under that technique, both cluster sampling and simple random sampling methods were used. People for the sample were selected using multi-stage cluster sampling and simple random sampling techniques. At the first stage, 2 Divisional Secretariat Divisions which were named Mahiyanganaya and Rideemaliyadda from 15 Divisional Secretariat Divisions were selected randomly. At the second stage of the cluster sampling, eight Grama Niladhari domains related to Mahiyanganaya and Rideemaliyadda divisional Secretariats were randomly selected for the study. They are Giradurukotte, Galporuyaya, Diwulapelessa, Aluyatawela, Serana, Gemunupura, Keselpotha north and Senevigama Grama Niladhari domains. The number of people from each Grama Niladhari domain was decided by proportional allocation method and a random procedure was applied to select the final unit for the sample.
Out of the two selected Mahiyanganaya and Rideemaliyadda Divisional Secretariat Divisions, we randomly selected $8 \mathrm{GN}$ Divisions with $4 \mathrm{GN}$ Divisions from each DS Divisions. Accordingly, there are 14605 persons in these 8 selected GN domains out of which the researcher planned to take a sample of 384. After considering the ratios for each GN domain, the researcher tried to include 224 persons from the selected GN Divisions of the Mahiyanganaya Divisional Secretariat and 160 persons from the selected GN Divisions of the Rideemaliyadda Divisional Secretariat into the 384 sample. However, the researcher was able to connect 210 persons from the GN Divisions relevant to Mahiyanganaya DS Division and only 151 persons from the GN Divisions relevant to Rideemaliyadda DS Division.

\section{Data collection methods}

Both primary and secondary data sources were used for this study. A structured questionnaire was the major primary data collection tool used for collecting needed data. Before the sample survey, a pilot survey was conducted for pretesting the questionnaire. It convinced to discover shortcoming of the questionnaire and to make the modification. The questionnaire consists of 4 major sections. The first section contains the personal information of those who have been diagnosed with kidney disease. The second section focuses on six major issues of clinical information of individuals and the third section focuses on information on their behavior. Individual's environmental activities were focused on in the last section.

\section{Conceptual framework}

A Conceptual framework is an analytical tool with several variations and contexts. It can be applied in different categories that require an overall picture.

\section{Figure 1: Conceptual Framework}

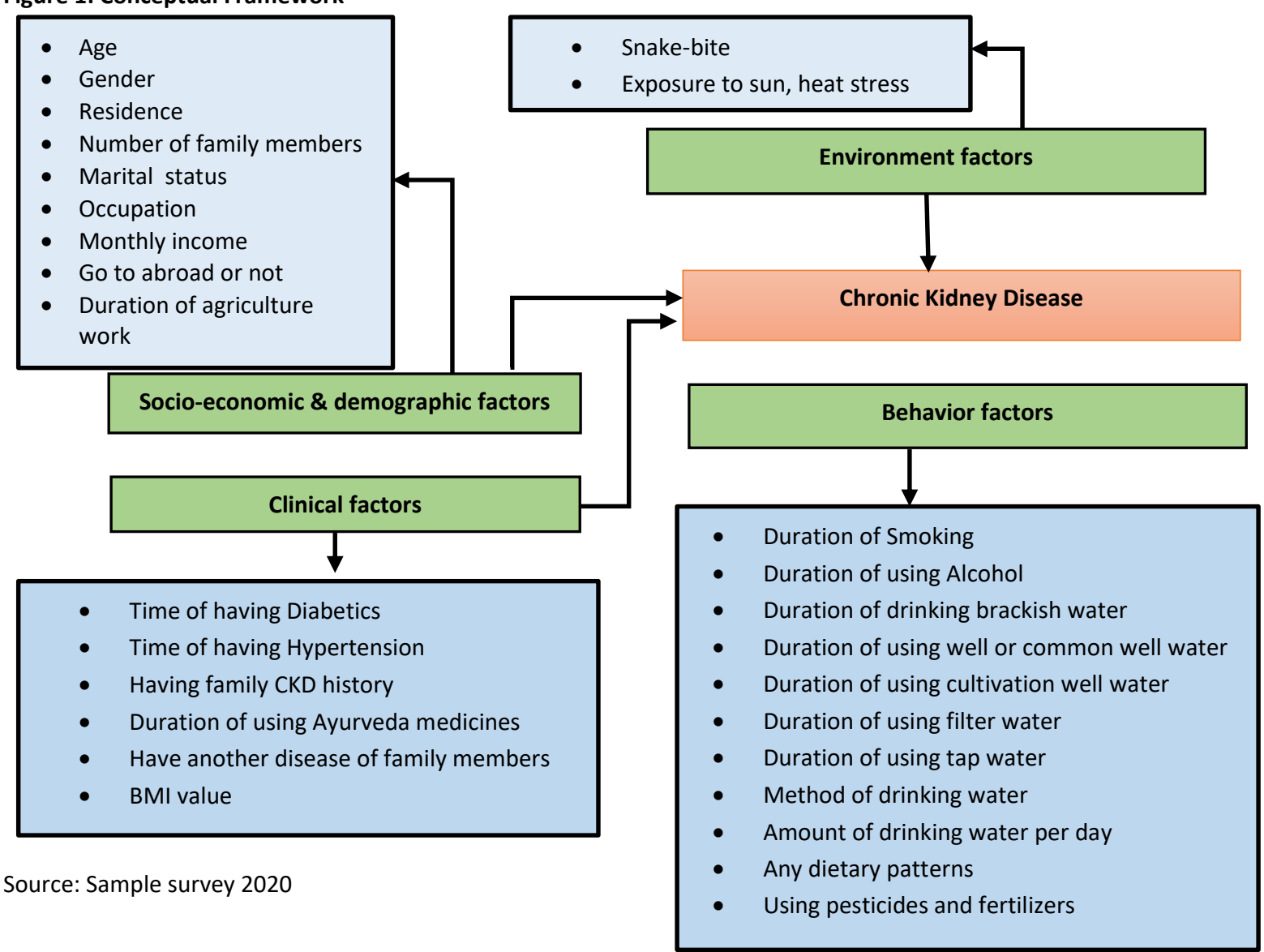


When considering the conceptual framework, the researcher developed the following hypothesis based on the literature.

$\mathrm{H}_{1}$; There is a relationship between socio-economic \& demographic factors on CKD.

$\mathrm{H}_{2}$; There is a relationship between clinical factors on CKD.

$\mathrm{H}_{3}$; There is a relationship between behavioral factors on CKD.

$\mathrm{H}_{4}$; There is a relationship between environmental factors on CKD.

The empirical literature on CKD mainly identified the determinants of CKD. Socio-economic \& demographic factors, Clinical factors, Behavior factors, and Environment factors are the main areas of explaining the profile of CKD patients. Under Socio-economic \& demographic characteristics we considered gender, age, occupation, income were some important characteristics relating to CKD. Time of having diabetes, Time of having high blood pressure, Duration of using Ayurveda medicines, Family history of kidney failure, and also BMI are some of the important clinical factors identified about CKD under empirical studies. As well as, under behavior factors or lifestyle factors, drinking water, Smoking and using alcohol, Use of pesticides, Use of heavy metals are some important characteristics relating to CKD. Further, Snakebite and geographical distribution are some of the important environmental factors identified related to CKD under the empirical studies.

\section{Data analysis}

The gathered data were analyzed by using Statistical Package for Social Science (SPSS) software. Binary Logistic Regression modal was used to achieve the main objective of identifying factors that affect CKD in Badulla district.

A binary Logistic Model was used to identify the factors affecting CKD. The binary dependent variable is having kidney disease (129 respondents) and not having kidney disease (232 respondents). The analysis provides the probabilities/ odds ratios of having kidney disease due to each factor. The

\section{RESULTS AND DISCUSSION}

Table 3 represents the descriptive statistics of the present study.

\section{Table 3: Descriptive statistics}

\begin{tabular}{|c|c|c|}
\hline Variable & Category & Proportion \\
\hline \multirow[t]{2}{*}{ Gender } & Female & $47.92 \%$ \\
\hline & Male & $52.08 \%$ \\
\hline \multirow[t]{5}{*}{ Age } & $18-36$ & $17.73 \%$ \\
\hline & $37-55$ & $32.41 \%$ \\
\hline & $56-74$ & $38.50 \%$ \\
\hline & $75-93$ & $10.25 \%$ \\
\hline & $94-112$ & $1.11 \%$ \\
\hline \multirow[t]{6}{*}{ Number of family members } & One & $3.32 \%$ \\
\hline & Two & $15.51 \%$ \\
\hline & Three & $21.33 \%$ \\
\hline & Four & $32.41 \%$ \\
\hline & Five & $18.28 \%$ \\
\hline & Six & $9.14 \%$ \\
\hline \multirow[t]{4}{*}{ Marital status } & Married & $71.47 \%$ \\
\hline & Unmarried & $15.24 \%$ \\
\hline & Divorced & $2.49 \%$ \\
\hline & Widow & $10.80 \%$ \\
\hline \multirow[t]{3}{*}{ Main occupation } & Agriculture & $30.19 \%$ \\
\hline & Small business & $10.53 \%$ \\
\hline & Government & $10.80 \%$ \\
\hline
\end{tabular}

Binary Logistic Regression model is used in the analysis as follows.

$$
\begin{aligned}
& \operatorname{logit}\left(p_{1}\right)=\log \left(\frac{p_{1}}{1-p_{1}}\right)=\sum_{i}^{n} \beta_{i} \\
& i=1,2, \ldots \ldots \ldots \ldots, n \\
& \mathrm{i}= \\
& P=\left(p_{1}\right)^{y}\left(1-p_{1}\right)^{1-y}, \ldots \ldots \ldots, \mathrm{n} \\
& {\left[\frac{1}{1+e^{\alpha}}\right]^{1-y} P=\left[\frac{e^{\alpha}}{1+e^{\alpha}}\right]^{y}} \\
& =e^{x y}\left[\frac{1}{1+e^{x}}\right]=e^{x y}\left(1+e^{x}\right)^{-1} \mathrm{P}=\left[\frac{\mathrm{e}^{\alpha}}{1+\mathrm{e}^{\alpha}}\right]^{\mathrm{y}}\left[\frac{1}{1+\mathrm{e}^{\alpha}}\right]^{1-\mathrm{y}}
\end{aligned}
$$

p1 shows the probability of having kidney disease and (1-p1) shows the probability of not having kidney disease. P shows the total probability of having and not having kidney disease. The parameters of the above model describe the log odds ratios (probability of being something relative to not being). If the odds ratio is higher than 1 , it implies that success is more likely than failure. If it is lesser than 1 , it implies that failure is more likely than success.

Odds ratio $\frac{\bar{Y}}{1-\bar{Y}}=e^{\propto}$ Probability of having Kidney<smiles>CC(C)=[Te]</smiles>
disease

Probability of not having kidney disease

$W=\frac{\left(\widehat{\alpha}-\propto_{0}\right)^{2}}{I(\widehat{\alpha})^{-1}}$ Wald test is used to test the statistical significance of the estimators.

In addition, the Chi-Squared test was used to identify the association between variables. Further, Descriptive statistical analyzing techniques are used to identify the specific characteristics of CKD. 


\begin{tabular}{llr}
\hline & Private & $11.63 \%$ \\
& Pension & $7.48 \%$ \\
& Unemployment & $23.82 \%$ \\
& Student & $5.54 \%$ \\
\hline Have family CKD patients & Yes & $22.22 \%$ \\
& No & $77.78 \%$ \\
\hline BMI value & Bellow 18.5 & $2.49 \% /$ \\
& $18.5-24.9$ & $80.61 \%$ \\
& $25.0-29.9$ & $14.68 \%$ \\
& Above 30.0 & $2.22 \%$ \\
\hline Snakebite & Yes & $21.88 \%$ \\
& No & $78.12 \%$ \\
\hline
\end{tabular}

Source: Sample survey 2020

Under the variable of gender in this study majority of respondents were females and it shows 47.92 percent in the whole sample and 52.08 percent were males. According to this study, the majority of respondents are between the ages of 56 and 74 . They represent 38.50 percent of the whole sample. In this study, we have found that the majority of families have four family members. That category indicates 117 sample elements from 361. It is 32.41 percent. When considering this selected sample, the majority of persons are married and they represent 71.47 percent of the whole sample. Furthermore, 30.19 percent of people have been engaged in agriculture for a long time or part-time. Accordingly, it appears that the majority of the people in the Mahiyanganaya and Rideemaliyadda Divisional Secretariats are engaged in agriculture and that situation does not seem to change much depending on the main occupation, age, or Figure 2: Prevalence of Chronic Kidney Disease gender. Having a family history of CKD category indicates only 80 sample elements from 361 . It is 22.16 percent. Further, from whole sample elements (361 respondents) 77.84 percent indicate not having a family history of CKD (281 respondents). Under the variable of BMI value in this study majority of respondents were included in the $18.5-24.9$ category. When we are considering the snake bite variable, the majority of people have not faced snake bite situations and it shows 78.12 percent in the whole sample and 21.88 percent have faced snake bite situations.

\section{Key characteristics of the sample}

The main purpose of this study to identify the factors that affect CKD in Badulla district. The dependent variable in the study is the prevalence of CKD measured as a binary variable.

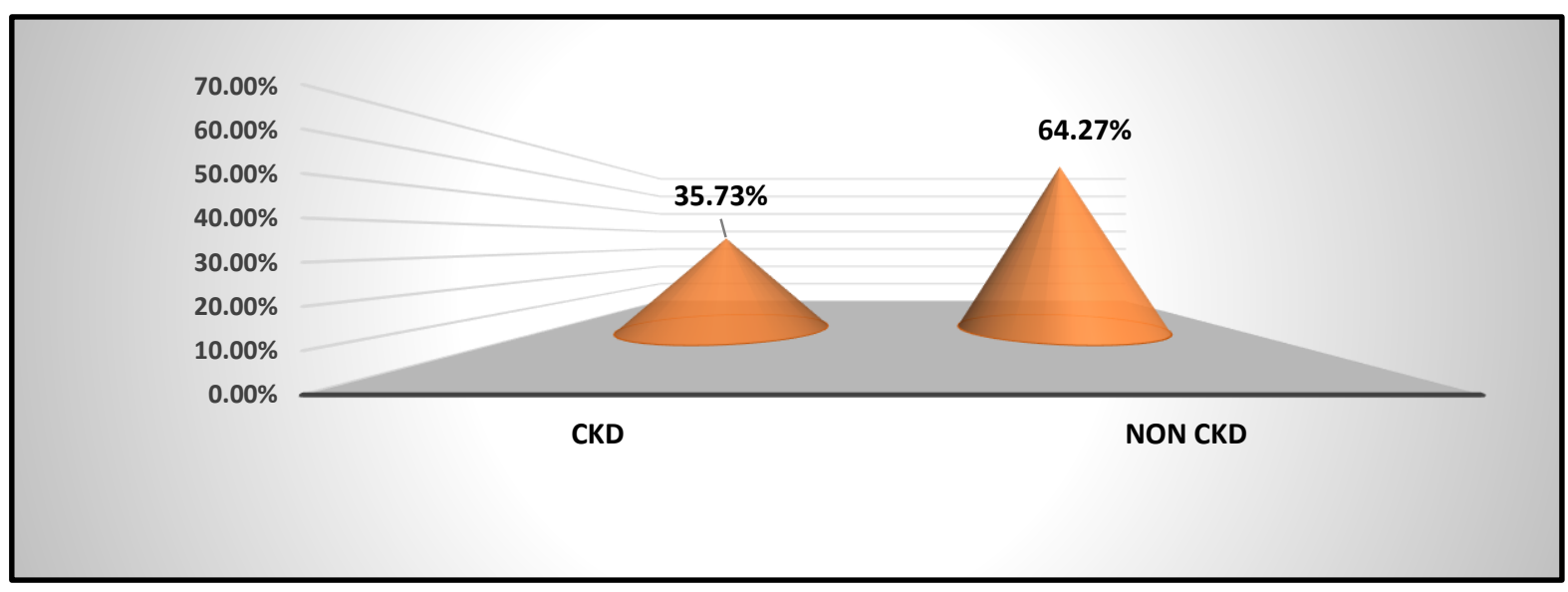

Source: Sample survey 2020

The CKD patients of the selected sample were recorded as 35.73 percent. As well, 64.27 percent out of total respondents was recorded for not having CKD. It was evident that a

Figure 3: Prevalence of Kidney Disease based on gender

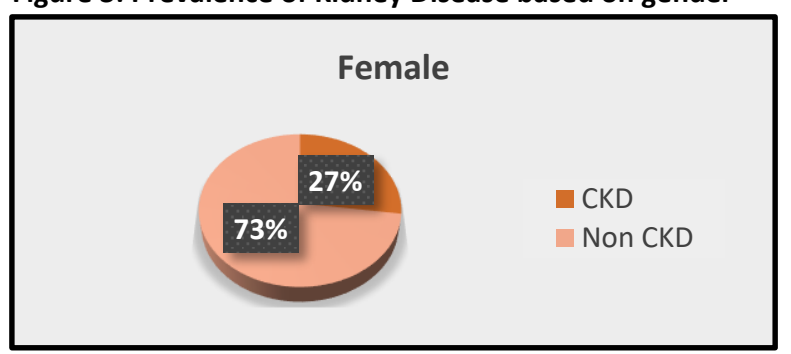

Source: Sample survey 2020 considerable percentage in the sample represents the group having CKD enabling the study to identify various factors that affect the prevalence of CKD.

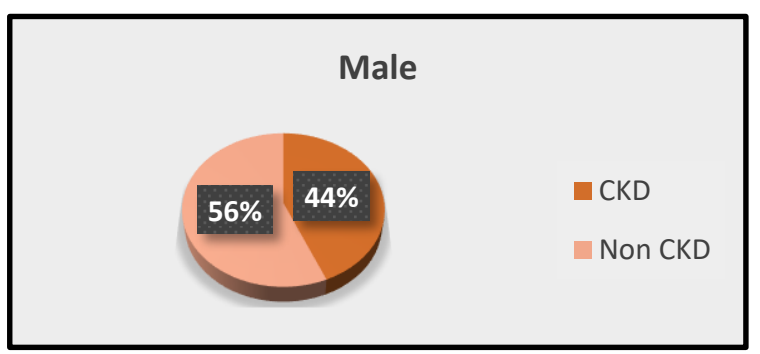


Considering the demographic profile, the sample includes both males and females representing $52.08 \%$ and $47.92 \%$ respectively. Figure 3 clearly shows that percentage of having CKD for males (44\%) is higher than the percentage of having CKD for females (27\%). There is a significant difference between males and females persons who are suffering from

Table 4: Prevalence of kidney disease by main occupation and engagement of agriculture work with the main occupation

\begin{tabular}{|c|c|c|c|c|c|c|c|c|}
\hline & & & \multicolumn{3}{|c|}{ Doing Agriculture work } & \multicolumn{3}{|c|}{ Not doing Agriculture work } \\
\hline & & & CKD & Non-CKD & Total & CKD & Non-CKD & Total \\
\hline \multirow{7}{*}{$\begin{array}{l}\text { Main } \\
\text { tion }\end{array}$} & \multirow[t]{7}{*}{ Occupa- } & Agriculture & $57 \%$ & $43 \%$ & $100 \%$ & $0 \%$ & $0 \%$ & $0 \%$ \\
\hline & & Small business & $29 \%$ & $71 \%$ & $100 \%$ & $0 \%$ & $100 \%$ & $100 \%$ \\
\hline & & Government & $24 \%$ & $76 \%$ & $100 \%$ & $9 \%$ & $91 \%$ & $100 \%$ \\
\hline & & Private & $16 \%$ & $84 \%$ & $100 \%$ & $30 \%$ & $70 \%$ & $100 \%$ \\
\hline & & Pension & $28 \%$ & $72 \%$ & $100 \%$ & $11 \%$ & $89 \%$ & $100 \%$ \\
\hline & & Unemployment & $51 \%$ & $49 \%$ & $100 \%$ & $0 \%$ & $100 \%$ & $100 \%$ \\
\hline & & Student & $0 \%$ & $100 \%$ & $100 \%$ & $7 \%$ & $93 \%$ & $100 \%$ \\
\hline
\end{tabular}

Source: Sample survey 2020

Considering the main occupation, the majority of people in the Mahiyanganaya and Rideemaliyadda Divisional Secretariats $(30.2 \%)$ are engaging with agricultural activities as their main occupation. According to table $3,57 \%$ of them are suffering from kidney disease. When only kidney patients are considered 48.06 percent of them are doing only agriculture kidney disease. It is about 17 percent. It appears that male persons in these areas are at higher risk of developing kidney disease and gender. disease. So, there may be a significant association between work. Accordingly, it appears that the majority of the people in the Mahiyanganaya and Rideemaliyadda Divisional Secretariats are engaged in agriculture and that situation does not seem to change much depending on the main occupation, age, or gender. Therefore, when considered the agricultural work, it implies more significance for Kidney disease.

Figure 4: prevalence of kidney disease by smoking habit

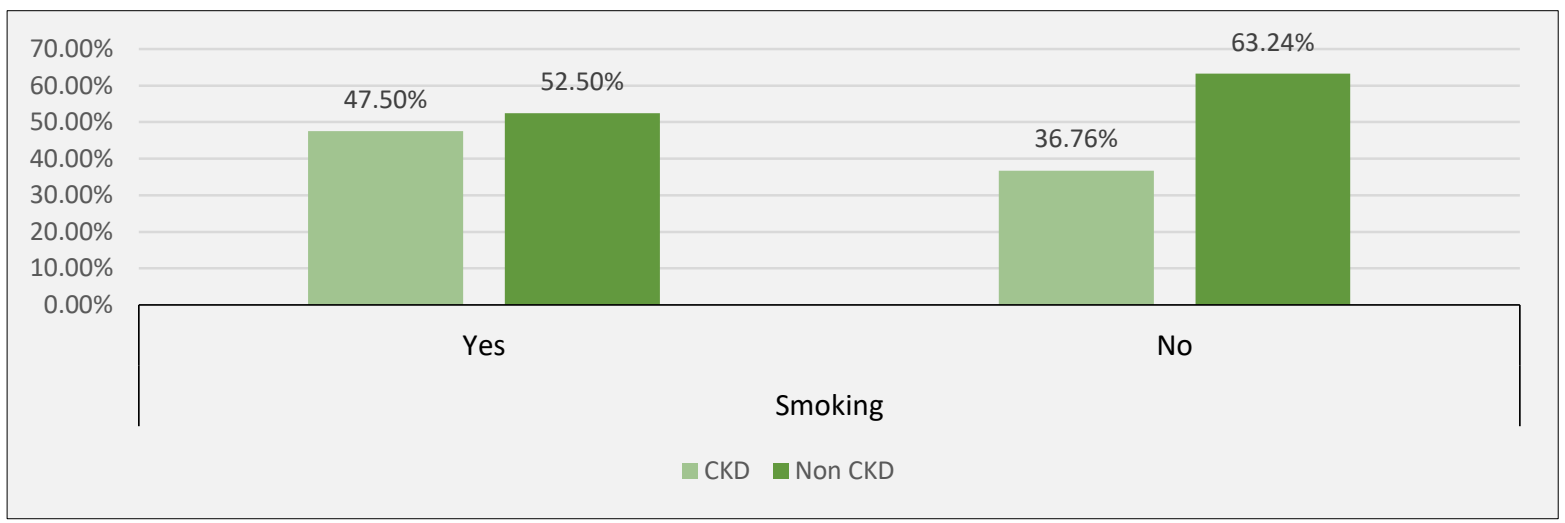

Source: Sample Survey 2020

Figure 5: prevalence of kidney disease by alcohol usage

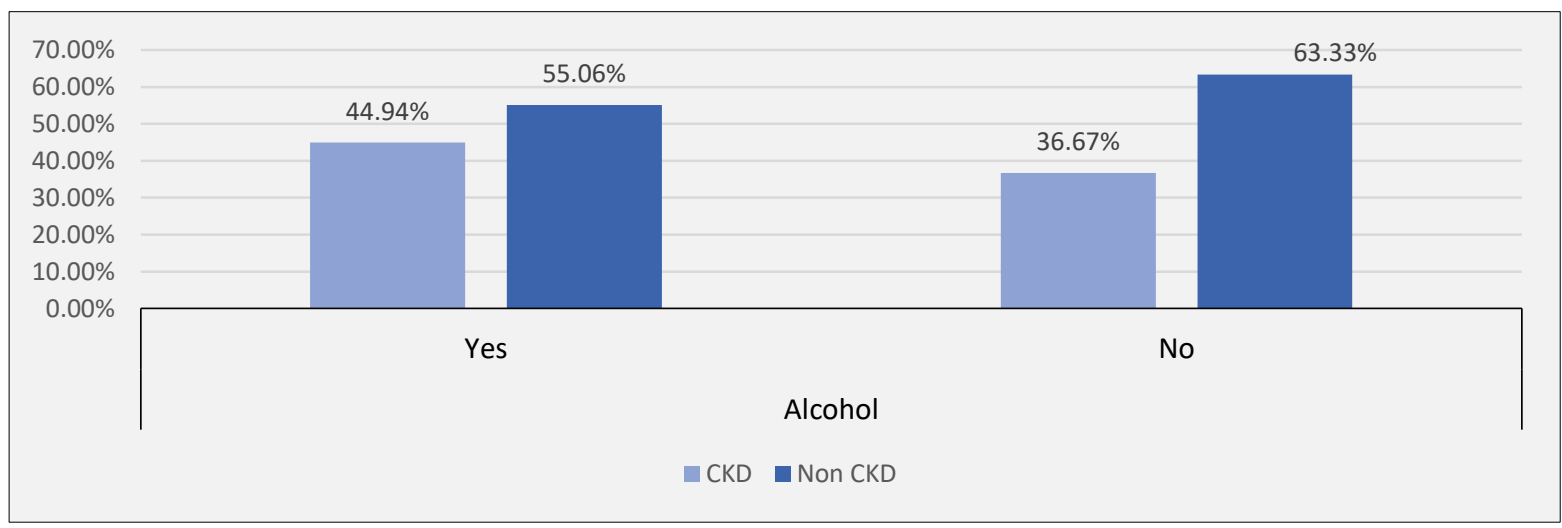

Source: Sample Survey 2020

Smoking and alcohol use are commonly referred to as drug use. Suppose that only men still use alcohol and smoke in Sri Lanka. Also, none of the women found in this sample use the drug. Therefore, after considering only male people in this sample, it is possible to identify how drug use affects kidney disease.
Regarding the smoking habit, the majority of males, indicating 64 percent of males in the sample are smoking. The highest percentage (47\%) of kidney patients is found for the smoking group and it is $36.76 \%$ for the non-smoking group. There is a significant difference between smokers and nonsmokers in the prevalence of disease showing about 10.14 percent of the difference. Therefore, smokers may be more likely to develop kidney disease than non-smokers. 
Similarly, considering consumption of alcohol, the majority of males indicating approximately 84 percent of males in the sample are using alcohol. As given in figure 7, nearly, 45 percent of people who use alcohol can be diagnosed with kidney disease while 36.67 percent of people who do not use alcohol can be diagnosed with kidney disease. Accordingly, it can be identified that people who use alcohol may be more likely to have kidney disease than people who do not use alcohol.

Accordingly, both smoking and alcohol usage may have a significant effect on kidney disease. Also, since the drug is used by male persons, kidney disease seems to have a significant effect on males.

\section{Factors affecting the prevalence of CKD}

This chapter was focused on identifying the impacting important factors to the CKD in Badulla district in Sri Lanka. The above objective has been achieved by creating an appropriate regression model. The binary logistic regression model is a suitable model for when the dependent variable is contained with a binary response.

In the study, the dependent variable carries two possible outcomes, "having CKD" and "not having CKD". So the most suitable statistical analysis technique for this study is the "Binary logistic regression model".

This study has used 28 independent variables and all of them are categorical explanatory variables with two or more categories. In this study, the researcher was used to enter the selection procedure to identify the most suitable model that explains the data set.

These 28 categorical independent variables are Gender, Age, Residence, Number of family members, Marital status, Main occupation, Go abroad or not, Duration of agricultural work, Monthly family income, Having family CKD history, Time of having diabetics, Time of having high blood pressure, Duration of using Ayurveda medicines, Have another disease of family members, BMI value, Duration of smoking, Duration of using alcohol, Duration of drinking brackish water, Duration of using well or common well water, Duration of using cultivation well water, Duration of using filter water, Duration of using tap water, Method of drinking water, Amount of drinking water per day, Any diet planning, Using fertilizers or not, Exposure to sun heat and also Snakebite.

Before fitting the binary logistic model for this study, it needs to check the relationship of the independent variables with the dependent variables. For that, a chi-square test was used to check the relationship between categorical independent variables with given dependent variables.

In this study, Pearson's chi-square test is used to check which independent variable has a significant association with the dependent variable. After considering the following hypothesis and decision rule, we can make the final results that are given below.

o Hypothesis

$\mathrm{HO}$ : There is no association between CKD and the Independent variable.

$\mathrm{H} 1$ : There is an association between CKD and the Independent variable.
Finally, we identified that out of 28 independent variables, residence, the number of family members, go abroad or not, having family CKD history, have another disease of family members, BMI, duration of using well or common well water, duration of using filter water, any diet planning and also snake bite do not have any association between the dependent variable. Therefore, significant 18 variables want to use in our model fitting process.

After checking the relationship between dependent and independent variables, the next step was to remove the variables consisting of Multicollinearity. Multicollinearity generally occurs when there are high correlations between two or more predictor variables. In other words, one predictor variable can be used to predict the other. For achieving this purpose Chi-square test was used. Finally, after considering those results, the 3 independent variables were used for fitting the final binary logistic regression model. They are Duration of using Alcohol, Duration of using Ayurveda medicines, and Amount of drinking water.

Then, the enter method is used to identify the factors which affect CKD in Badulla district of Sri Lanka. The initial step of the binary logistic regression is fitting the null model. But we are not able to consider the null model as best fitted model. Then, we have found 3 independent variables as the significant variables which are consisted of an association between the dependent variable, and those selected significant three variables were individually fit the models. Under the binary logistic regression model with one variable, all 3 variables were formed, significant models. However, it is essential to identify the best-fitted one variable model among those three models. Therefore, we will be considering the model that has the highest $\mathrm{G} 2$ value, and the greatest $\mathrm{G} 2$ value is assumed to fit the best model. In this study, the highest $\mathrm{G} 2$ value is 78.996 which contains the variable "Amount of drinking water per day". According to this result, we can be identified the variable Amount of drinking water that should be in the model.

After identifying that the variable Amount of drinking water per day should be in the one variable model, we will be fitting the two-variable model by including the Amount of drinking water. After that, other independent variables should be added to the model individually with the selected variable. According to this study, we can be identified the variable Amount of drinking water per day and Duration of using alcohol should be in the model.

The selected best fit model has considered two main effects. Then we want to check the interaction effect is significant or not as the next step. In this model, there is only one twoway interaction model. Because there are only two main effects in the selected model. But in here, the P-value of this interaction model was not less than 0.05 alpha level. (1.000 $>0.05)$. Therefore we do not consider that interaction term to the best fit model.

So finally we have identified that the best-fitted model for our data is the two variables binary logistic model without interaction terms.

The binary logistic regression model was derived to identify the factors affecting CKD in Badulla district as follows (Table 5). 
Table 5: Selected variables for the final fitted model

\begin{tabular}{|c|c|c|c|c|c|c|c|}
\hline Parameter & B & S.E. & Wald & df & Sig. & $\operatorname{Exp}(\beta)$ & Reference \\
\hline $\begin{array}{l}\text { Amount of drinking water } \\
\text { per day }\end{array}$ & & & 55.819 & 4 & 0.000 & & Bellow 1 liters \\
\hline $\begin{array}{l}\text { Greater than or equal } 4 \text { li- } \\
\text { ters (1) }\end{array}$ & -3.633 & 0.643 & 31.910 & 1 & 0.000 & 0.026 & \\
\hline 3 to 4 liters & -2.660 & 0.466 & 32.642 & 1 & 0.000 & 0.070 & \\
\hline 2 to 3 liters & -1.809 & 0.422 & 18.410 & 1 & 0.000 & 0.164 & \\
\hline 1 to 2 liters & -0.923 & 0.445 & 4.289 & 1 & 0.038 & 0.397 & \\
\hline Duration of using Alcohol & & & 13.429 & 4 & 0.009 & & Never \\
\hline Bellow 4 years $(1)$ & -1.777 & 1.140 & 2.428 & 1 & 1.119 & 0.169 & \\
\hline 4 to 7 years & 0.045 & 0.579 & 0.006 & 1 & 0.938 & 1.046 & \\
\hline 7 to 10 years & 0.554 & 0.408 & 1.845 & 1 & 0.174 & 1.741 & \\
\hline $\begin{array}{l}\text { Greater than or equal } 10 \\
\text { (4) }\end{array}$ & 0.905 & 0.295 & 9.416 & 1 & 0.002 & 2.471 & \\
\hline Constant & 0.875 & 0.386 & 5.137 & 1 & 0.023 & 2.398 & \\
\hline
\end{tabular}

Source: sample survey 2020

From the number of variables considered at the initial step, only a few have to be retained for the model due to the attempt to overcome the problem of violating Multicollinearity assumption while some too are left due to the relationship was insignificant with kidney disease. For the best-fitted model, significant variables are given in table 4 . They are the amount of drinking water and duration of alcohol usage. There is a significant negative relationship between all levels of amount of drinking water per day and having kidney disease. As well as, people who have been drinking alcohol for less than 4 years have a negative relationship with having kidney disease. But, another duration of using alcohol has a positive relationship with having kidney disease.

\section{According to the amount of drinking water per day}

- When all other factors are constant, 5.96 percent of people who drink more than 4 liters of water per day have kidney disease compare to people who drink less than 1 liter per day. People who drink less than 1 liters of water per day have a $70.57 \%$ chance of having kidney disease. Compared to people who drink more than 4 liters per day, the probability of having kidney disease is approximately 12 times higher for people who drink less than 1 liters per day.

- When all other factors are constant, people who drink between 3 and 4 liters of water per day have a 14.37 percent chance of having kidney disease, and compared to that group, the probability of having the disease is 5 times higher for people who drink less than 1 liter per day.

- When all other factors are constant, people who drink between 2 and 3 liters of water per day have a 28.21 percent chance of having kidney disease, and compared that group probability of having kidney disease is twice for people who drink less than 1 liter per day.

- When all other factors are constant, people who drink between 1 and 2 liters of water per day have a
48.80 percent chance of having kidney disease compared to people who drink less than 1 liter per day.

According to Duration of using Alcohol

- When all other factors are constant, 28.86 percent of people who have been drinking alcohol for less than 4 years are suffering from kidney disease compared to people who are never drinking alcohol.

- When all other factors are constant, people who have been drinking alcohol between 4 and 7 years have a 71.5 percent chance of having a kidney and it is higher compared to those who never use alcohol.

- When all other factors are constant, people who have been drinking alcohol between 7 and 10 years have an 80.67 percent chance of having kidney disease and it is higher than those who never use alcohol.

- When all other factors are constant, people who have been drinking alcohol for more than 10 years have an 85.57 percent chance of having kidney disease and it is higher compared to people who are never drinking alcohol.

\section{DISCUSSION}

- In chapter two, we identified how researchers have uncovered how different factors affect kidney disease.

- Accordingly, let us first consider the socio-economic and demographic factors. The majority of researchers found that male people were more likely to have kidney disease than women when it came to gender. But according to Kafle et al. (2019), women have a higher risk of developing kidney disease than men. However, this study found that men are more likely to develop kidney disease.

- Next, when considering age, the majority of researchers say that age is another factor that affects kidney disease. As the same result, the study found that age 
is a risk factor for kidney disease. It was also revealed that the majority of kidney patients are in the age group of 56 and 74 years.

- When it comes to occupation, all researchers have found that farming as a job has a major impact on kidney disease. Consistent with that statement, this study also shows that farmers are more likely to develop kidney disease.

- When considering clinical factors, Wanigasuroya et al. (2017) said that having a family history of kidney disease is a genetic factor. Jha et al. (2013) also said that there may be a genetic influence on kidney disease. However, it is not clear from this study whether people with or without genetic predisposition are more likely to develop kidney disease. But we can speculate that this disease, like other non-communicable diseases, may have a genetic influence.

- Even when a chronic disease such as diabetes and high blood pressure are taken into account, the majority of studies have shown those diseases such as diabetes and high blood pressure have a significant effect on kidney disease. This study also confirmed that high blood pressure and diabetes have a significant effect on kidney disease.

- Behavioral factors include smoking and alcohol consumption, which can be identified as two factors that only affect male people. In identifying the factors that contribute to the spread of kidney disease, previous researchers also found that drugs and tobacco affect kidney disease. As well as, the study also found that drug use has a significant effect on kidney disease. Therefore, drug use can be identified as one of the main reasons why male people are more prone to kidney disease.

- Drinking water is also one of the most important factors. Previous studies have shown that different sources of drinking water affect kidney disease. Kafle et al. (2019) said the use of groundwater has a positive effect on kidney disease. Further Jayasekara et al. (2016) said that natural spring water has less effect on the spread of kidney disease. However, this study focused on the amount of water consumed per day. It was revealed that the amount of water consumed per day also has a clear effect on kidney disease. This shows that our body needs more amount of water to stay healthy. But, according to previous studies, if the water sources they use are harmful to the body, it is also dangerous to drink too much water. Therefore, the responsible parties should know that more attention should be paid to this water issue.

\section{CONCLUSION}

The main objective of this study is to identify the factors affecting CKD in Sri Lanka with special reference to Badulla district by using 361 respondents selected for the sample. Descriptive statistics technique and binary logistic regression model were used to identify the factors. Gender, age, residence, marital status, occupation, income under socio-economic and demographic profile, diabetics, hypertension, family history of CKD failure, use Ayurveda medicines, BMI under clinical profile and smoking, using alcohol, drinking water, dietary patterns, use of pesticides and fertilizers under behavior profile and also snake bite, exposure to sun heat under environment profile were studied comprehen- sively through this attempt. Descriptive found that age, gender, doing agriculture work, use medications for diabetes and high blood pressure, smoking and using alcohol habits, amount of drinking water per day, and exposure to sun heat are associated with having kidney disease. But snake bites may not be a significant factor in kidney disease. Binary logistic regression found that a significant impact of the amount of water drink per day and duration of alcohol usage on kidney disease. An increased amount of water consumed per day has a significant impact on decrease the prevalence of kidney disease. An increase in the duration of alcohol usage is significantly associated with an increase in the prevalence of kidney disease.

Furthermore, according to this study results, the Amount of water per day and the Duration of using alcohol are the selected variables for the model through the binary logistic regression.

\section{Amount of drinking water per day}

According to the findings of the main analysis techniques, the Amount of drinking water per day is the first selected variable for the model. According to medical records, adequate drinking water is one of the most important factors to our body. If not, it will cause damage to the kidneys. Because kidneys are important parts of the human body's urinary system. It is also verified from the previous analysis. According to those results, people who drink more than 4 liters of water per day have a very small chance ( 6 percent) of having kidney disease rather than 1 liter per day. According to that, the kidney patients who are in the sample, not drink an adequate amount of water per day. After direct conversations, we identified these considerable $\mathrm{GN}$ divisions and those people are very busy with their agriculture work, and every day they are out of the home. Not only that they are very hard working. So, may be they have missed thinking about their healthy life.

\section{Using Alcohol}

There may be the drinking alcohol factor that influences kidney disease. In this study, the majority of kidney patients are male and among the majority of male patients are drinking alcohol. These selected eight $\mathrm{GN}$ divisions are rural and most of them are not highly educated. And also, after direct conversations, we identified that majority of male kidney patients have been addicted to alcohol for a long time. Most people said that they drank alcohol daily to forget their tried. So it may be caused an increase in the number of male kidney patients.

According to the above findings, the following suggestions are made as to the final contribution of the study.

- People should be educated about an adequate amount of drinking water for the human body per day.

- Male persons should reduce their alcohol consumption and the government should implement awareness programs explaining the harmful effects of alcohol.

- The government should take the action to provide healthy filter water for all persons quickly and it should provide free.

- The government should hold clinics for awareness of people about kidney disease and early notification of having kidney disease may convince them to overcome the situation. The government should pay more attention to the physical and mental discomfort suffered by kidney patients due to their disease. 
- People should have a responsibility to maintain a healthy life and timely received treatment.

\section{REFERENCES}

Abraham, G., Varughese, S., Thandavan, T., lyengar, A., Fernando, E., Naqvi, S. A., ... \& Kafle, R. K. (2016). Chronic kidney disease hotspots in developing countries in South Asia. Clinical kidney journal, 9(1), 135-141.

Bapat, U., Nayak, S. G., \& Kedleya, P. G. Abraham, G., Varughese, S., Thandavan, T., lyengar, A., Fernando, E., Naqvi, S. A., ... \& Kafle, R. K. (2016). Chronic kidney disease hotspots in developing countries in South Asia. Clinical kidney journal, 9(1), 135-141. (2008).

Bapat, U., Nayak, S. G., \& Kedleya, P. G. (2008). Demographics and social factors associated with acceptance of treatment in patients with chronic kidney disease. Saudi Journal of Kidney Diseases and Transplantation, 19(1), 132.

Chandrajith, R., Nanayakkara, S., Itai, K., Aturaliya, T. N. C., Dissanayake C. B., Abeysekera, T., ... \& Koizumi, A. (2011). Chronic kidney diseases of uncertain etiology (CKD) in Sri Lanka: geographic distribution and environmental implications. Environmental geochemistry and health, 33(3), 267-278.

Chronic Kidney Disease. (n.d.). Retrieved from World Kidney Day: file:///E:/KIDNEY/Chronic\%20Kidney\%20Disease\%20\%20World\%20Kidney\%20Day.htm

Chronic Kidney Disease. (n.d.). Retrieved from Wikipedia: https://en.wikipedia.org/wiki/ChronicKidneydisease

Coresh, J., Selvin, E., Stevens, L. A., Manzi, J., Kusek, J. W., Eggers, P., ... \& Levey, A. S. (2007). Prevalence of chronic kidney disease in the United States. Jama, 298(17), 2038-2047.

Department of Census and Statistics. (n.d.). District Statistical Handbook. Retrieved from Statistical website of SriLanka: http://www.statistics.gov.lk/ref/HandbookDictionary

Divisional Secretariat-Mahiyanganaya. (n.d.). Retrieved from Ministry of Home Affairs:

http://mahiyanganaya.ds.gov.lk/index.php/en/administrativestructure/gn-divisions.html

District Secretariats of Sri Lanka. (n.d.). Retrieved from Ministry of Home Affairs-SriLanka: http://www.moha.gov.lk/web/index.php?lang=en

Duan, J., Wang, C., Liu, D., Qiao, Y., Pan, S., Jiang, D., ... \& Zhang, Y. (2019). Prevalence and risk factors of chronic kidney disease and diabetic kidney disease in Chinese rural residents: a cross-sectional survey. Scientific reports, 9(1), 1-11.

efforts to curb Kidney disease in NCP. (2019, March 07). Retrieved from Daily News: August 4, 2020, from https://www.dailynews.lk/2019/03/07/features/179499/effortscurb-kidney-disease-ncp

Elledge, M. F., Redmon, J. H., Levine, K. E., Wickremasinghe, R. J., Wanigasariya, K. P., \& Peiris-John, R. J. (2014). Chronic kidney disease of unknown etiology in Sri Lanka: A quest for understanding and global implications. In RTI Press Research Brief [Internet]. RTI Press.

Ellepola, Y. (2016, March 10). World Kidney Day. Retrieved from Talking Economics:https://www.ips.lk/talkingeconomics/2016/03/10/world -kidney-day-2016-what-more-can-sri-lanka-do-to-save-lives/

Foley, R. N., Murray, A. M., Li, S., Herzog, C. A., McBean, A. M., Eggers, P. W., \& Collins, A. J. (2005). Chronic kidney disease and the risk for cardiovascular disease, renal replacement, and death in the United States Medicare population, 1998 to 1999. Journal of the American Society of Nephrology, 16(2), 489-495.

Hettiarachchi, R., \& Abeysena, C. (2018). Association of poor social support and financial insecurity with the psychological distress of chronic kidney disease patients attending national nephrology unit in Sri Lanka. International journal of nephrology, 2018.

Jayasekara, K. B., Dissanayake, D. M., Sivakanesan, R., Ranasinghe, A., Karunarathna, R. H., \& Kumara, G. W. G. P. (2015). Epidemiology of chronic kidney disease, with special emphasis on chronic kidney disease of uncertain etiology, in the north-central region of Sri Lanka. Journal of Epidemiology, 25(4), 275-280.

Jha, V., Garcia-Garcia, G., Iseki, K., Li, Z., Naicker, S., Plattner, B., ... \& Yang, C. W. (2013). Chronic kidney disease: global dimension and perspectives. The Lancet, 382(9888), 260-272.

Johnson, C. A., Levey, A. S., Coresh, J., Levin, A., \& Eknoyan, J. G. L. (2004). Clinical practice guidelines for chronic kidney disease in adults: part
1. Definition, disease stages, evaluation, treatment, and risk factors. American family physician, 70(5), 869-876.

Kafle, K., Balasubramanya, S., \& Horbulyk, T. (2019). Prevalence of chronic kidney disease in Sri Lanka: A profile of affected districts reliant on groundwater. Science of The Total Environment, 694, 133767.

Kumela Goro, K., Desalegn Wolide, A., Kerga Dibaba, F., Gashe Fufa, F., Wakjira Garedow, A., Edilu Tufa, B., \& Mulisa Bobasa, E. (2019). Patient Awareness, Prevalence, and Risk Factors of Chronic Kidney Disease among Diabetes Mellitus and Hypertensive Patients at Jimma University Medical Center, Ethiopia. BioMed Research International, 2019.

National Kidney Foundation. (n.d.). Retrieved from August 03, 2020, from https://www.kidney.org/kidneydisease/howkidneyswrk

Organization, W. H. (2018, April 20). The global burden of kidney disease and the sustainable development goals. Retrieved from August 5, 2020, from World Health Organization: https://www.who.int/bulletin/volumes/96/6/17-206441/en/

Peng, S., Shen, F., Wen, A., Wang, L., Fan, Y., Liu, X., \& Liu, H. (2019). Detecting Lifestyle Risk Factors for Chronic Kidney Disease With Comorbidities: Association Rule Mining Analysis of Web-Based Survey Data. Journal of medical Internet research, 21(12), e14204.

Rajapakse, S., Shivanthan, M. C., \& Selvarajah, M. (2016). Chronic kidney disease of unknown etiology in Sri Lanka. International Journal of occupational and environmental health, 22(3), 259-264.

Ranasinghe, A. V., Kumara, G. W. G. P., Karunarathna, R. H., De Silva, A P., Sachintani, K. G. D., Gunawardena, J. M. C. N., ... \& De Silva, M. V. C. (2019). The incidence, prevalence, and trends of Chronic Kidney Disease and Chronic Kidney Disease of uncertain etiology (CKDu) in the North Central Province of Sri Lanka: an analysis of 30,566 patients. BMC nephrology, 20(1), 338.

Rango, T., Jeuland, M., Manthrithilake, H., \& McCornick, P. (2015). Nephrotoxic contaminants in drinking water and urine, and chronic kidney disease in rural Sri Lanka. Science of the Total Environment, 518, 574-585.

Raveendran, A., \& Balarajah, S. Epidemiology of chronic kidney disease in the local population in Jaffna, Sri Lanka.

Soderland, P., Lovekar, S., Weiner, D. E., Brooks, D. R., \& Kaufman, J. S. (2010). Chronic kidney disease; associated with environmental toxins and exposures. Advances in chronic kidney disease, 17(3), 254-264.

Theories of Kidney Disease Confirmed. (n.d.). Retrieved from September 10, 2020, from Wake Forest Baptist Health: https://www.wakehealth.edu/About-Us/History/Firsts/Theories-ofKidney-Disease-Confirmed

Wanigasuriya, K. (2014). Update on uncertain etiology of chronic kidney disease in Sri Lanka's north-central dry zone. MEDICC Review, 16, 6165.

Wanigasuriya, K. P., Peiris-John, R. J., Wickremasinghe, R., \& Hittarage, A. (2007). Chronic renal failure in North Central Province of Sri Lanka: an environmentally induced disease. Transactions of the Royal Society of Tropical Medicine and Hygiene, 101(10), 1013-1017.

Weerasekara, C. B. M. (2017). An empirical study on the socioeconomic factors affecting chronic kidney disease in Anuradhapura district (with special reference to Kabithigollewa).

Wimalawansa, S. J. (2015). Agrochemicals and chronic kidney disease of multifactorial origin: Environmentally induced occupational exposure disease. Int J Nephrol Kidney Failure, 1(2), 1-9.

Wimalawansa, S. J. (2019). Public health interventions for chronic diseases: cost-benefit modelizations for eradicating chronic kidney disease of multifactorial origin $(\mathrm{CKDmfo} / \mathrm{CKDu})$ from tropical countries. Heliyon, 5(10), e02309.

World Kidney Day. (n.d.). Retrieved from November 22, 2020, from https://www.worldkidneyday.org/about/world-kidney-day/

Yamagata, K., Ishida, K., Sairenchi, T., Takahashi, H., Ohba, S., Shiigai, T., ... \& Koyama, A. (2007). Risk factors for chronic kidney disease in a community-based population: a 10-year follow-up study. Kidney International, 71(2), 159-166.

(2012, March 24). Retrieved from August 10, 2020, from Daily News: http://archives.dailynews.1k/2012/03/24/news33.asp 
